\title{
Study of lithiation mechanisms of high performance carbon-coated Si anodes by in-situ microscopy
}

Zheng-Long Xu, ${ }^{\text {a }} \mathrm{Ke}$ Cao, ${ }^{\mathrm{b}}$ Sara Abouali, ${ }^{\mathrm{a}}$ Mohammad Akbari Garakani, ${ }^{\mathrm{a}}$ Jiaqiang Huang, ${ }^{\mathrm{a}}$ Jian-Qiu Huang, ${ }^{a}$ Elham Kamali Heidari, ${ }^{a}$ Hongtao Wang ${ }^{b^{*}}$ and Jang-Kyo Kim ${ }^{a^{*}}$

${ }^{a}$ Department of Mechanical and Aerospace Engineering, The Hong Kong University of Science and Technology, Clear Water Bay, Kowloon, Hong Kong

${ }^{\mathrm{b}}$ Institute of Applied Mechanics, Zhejiang University, Hangzhou 310027, P.R. China

*Address correspondence to mejkkim@ust.hk(J. K. Kim), htw@zju.edu.cn (H. Wang). 


\title{
Study of lithiation mechanisms of high performance carbon-coated Si anodes by in-situ microscopy
}

\begin{abstract}
Carbon coated $\mathrm{Si}(\mathrm{Si} / \mathrm{C})$ composites with a high $\mathrm{Si}$ content of $81 \mathrm{wt} . \%$ are synthesized by one-pot carbonization of the mixture containing commercial Si particles and polyvinylidene fluoride (PVDF) at an optimized temperature. The Si/C electrodes deliver a high cyclic capacity of 2003 $\mathrm{mAh} \mathrm{g}{ }^{-1}$ at $0.5 \mathrm{~A} \mathrm{~g}^{-1}$ after 50 cycles and an enhanced rate capability of $\sim 750 \mathrm{mAh} \mathrm{g}^{-1}$ at $4 \mathrm{Ag}^{-1}$ for over 200 cycles. The effect of ultrathin carbon coating on lithiation mechanisms of Si particles is evaluated using the in-situ transmission electron microscopy (TEM). It is revealed that the carboncoated Si particles undergo an isotropic to anisotropic transition during the initial lithiation, whereas such transition is not observed for the uncoated Si particle. The lithiation rate of Si/C is 3 to 4.5 times faster than that of uncoated $\mathrm{Si}$ with the same diameter, a testament to high rate capacities of $\mathrm{Si} / \mathrm{C}$ in real batteries. The flexible, amorphous carbon coating favorably alters the damage mode of Si particles from pulverization by multiple cracking to fracture by a single crack. The above findings offer fundamental understanding and practical guideline for designing carbon coatings of Si-based electrodes with much enhanced electrochemical performance.
\end{abstract}

Keywords: carbon coating; silicon particles; Li-ion batteries; in-situ TEM.

\section{Introduction}

Among many electrochemical energy storage devices, Li-ion batteries (LIBs) have gained widespread use in consumer electronics. To satisfy demanding applications like electric vehicles and smart-grids, however, next generation electrodes with higher energy/power densities, longer cycle life and lower manufacturing costs than what the current electrodes can offer should be developed [1-2]. Thanks to its many advantages, such as the high theoretic specific capacity of $3579 \mathrm{mAh} \mathrm{g}^{-1}$ at room temperature, natural abundance, environmental benignity and low working potential $(\sim 370 \mathrm{mV}), \mathrm{Si}$ has been considered one of the most promising alternatives to the conventional graphite anode [3]. Nevertheless, the electrodes made from Si suffer from poor electrochemical reversibility and low rate capacities arising from the following unfavorable mechanisms [4-6], which hinder its widespread implementations. (i) The large volume expansion over $300 \%$ occurring during the lithiation/delithiation cycles causes pulverization of the active 
materials and delamination of the electrodes from the current collectors. (ii) The low electrical conductivity $\left(10^{-3} \mathrm{~S} \mathrm{~cm}^{-1}\right)$ and ion diffusivity $\left(10^{-12} \mathrm{~cm}^{2} \mathrm{~s}^{-1}\right)$ of $\mathrm{Si}$ limit the high-rate performance of the electrodes. (iii) The solid electrolyte interface (SEI) layer formed on Si electrodes becomes unstable due to repeated expansion and contraction of $\mathrm{Si}$, causing low Coulombic efficiencies and fast capacity degradation.

Different forms of Si nanostructures [7-11] have been developed to address the volume expansion of $\mathrm{Si}$, the first issue in the above, thus demonstrating significantly improved electrochemical performance. A carbon coating on Si has been considered the most effective and feasible strategy to address the last two issues by contributing to the following ameliorating effects [12-13]: (i) the carbon sheath improves the current transport, thus enhancing the reaction kinetics; (ii) the soft carbon coating functions as the buffer to contain the volume expansion of Si during lithiation; (iii) the carbon shell prevents the Si particles from direct contact with the electrolyte, effectively discouraging the formation of SEI layers [12]; and (iv) the carbon coating serves as physical barrier to prevent aggregation of active materials during cycles. Even after a myriad of reports on carboncoated $\mathrm{Si}(\mathrm{Si} / \mathrm{C})$ electrodes [14-21], several critical issues still remain to be resolved: namely, (i) simple and cost-efficient manufacturing techniques with low-cost and commercially available materials should be developed; (ii) the amount of Si used in electrodes has not been sufficient to take advantage of its extremely high capacity [17-20]; (iii) little attention has been paid to surface functionalization and dispersion of aggregated Si nanoparticles, which is an important factor influencing the cyclic stability of the electrodes [21-23]; and (iv) the electronically insulating PVDF is often employed as binder for casting electrode materials, which adds an extra weight to the overall electrodes and causes polarization [16].

Although there exist many studies on carbon coating as a means to improve the electrochemical performance, few efforts have been made to explore the roles of carbon coating during electrochemical reactions and the structural evolution of Si particles upon reaction. The in-situ transmission electron microscopy (TEM) has emerged as an indispensable tool to probe in realtime the lithiation/delithiation process of electrodes on an atomic scale [24-25]. Following the recent in-situ TEM characterization of nanostructured Si and Si composites, like Si nanoparticles (NPs) [26-27], alucone/Si NPs [28], graphene/Si NPs [29], carbon nanofiber (CNF)/Si NPs [30] and $\mathrm{Si} / \mathrm{C}$ yolk/shell structure [31], this paper is dedicated to identifying the reaction mechanisms 
and morphological changes in Si/C NP electrodes in real-time. To the best of our knowledge, this is the first report of studying the amorphous carbon-coated Si particles by in-situ TEM.

High capacity Si/C electrodes with enhanced cyclic stability were synthesized by coating PVDF on modified Si NPs which were directly carbonized. The in-situ TEM analysis revealed abnormal lithiation behaviors in both the uncoated $\mathrm{Si}$ and $\mathrm{Si} / \mathrm{C}$ particle electrodes. The conductive carbon coating contributed significantly to the lithiation dynamics at initial stage and the enhancement of reaction kinetics by improving the electron/ion transport efficiencies. The cracking mechanisms in the electrodes were also established. These new findings can allow one to elucidate the capacity fading mechanisms and the limiting factors for better design of $\mathrm{Si} / \mathrm{C}$ composite electrodes.

\section{Experimental}

\subsection{Synthesis of $\mathrm{Si} / \mathrm{C}$ electrodes}

The agglomerated Si nanoparticles of average particle size 50-150 nm (Shanghai ST-Nano Science \& Technology) were monodispersed in aqueous solution by amino-silane functionalization followed by $\mathrm{F}$ ion mediation, according to our previous work [22]. To prepare $\mathrm{Si} / \mathrm{C}, 0.6 \mathrm{~g}$ of treated Si particles was mixed with $0.4 \mathrm{~g}$ PVDF as the carbon precursor and N-methyl-2-pyrrolidone (NMP) solvent using a magnetic stirrer overnight. The mixture was cast on a copper foil to form a composite film of $\sim 20 \mu \mathrm{m}$ in thickness, which was dried at $85^{\circ} \mathrm{C}$ in a vacuum oven overnight. The films were cut into pellets of $1.2 \mathrm{~cm}$ in diameter and carbonized at different temperatures ranging $550-950{ }^{\circ} \mathrm{C}$ for $1 \mathrm{~h}$ with a $\mathrm{N}_{2}$ gas flow in an electric tube furnace (Lindberg/Blue, $1700{ }^{\circ} \mathrm{C}$ ). The final products were designated as $\mathrm{Si} / \mathrm{C}-550, \mathrm{Si} / \mathrm{C}-750$ and $\mathrm{Si} / \mathrm{C}-950$ respectively, depending on the

carbonization temperature. The average mass loading of active materials was $\sim 1.0 \mathrm{mg} \mathrm{cm}^{-2}$, which is generally higher than those of previous reports on similar Si NPs-based electrodes [16,21].

\subsection{Characterization and electrochemical tests}

The absorption spectra were obtained by Fourier transform infrared spectroscopy (FTIR, Perkin Elmer Spectrum One). The functionalized Si/PVDF films or Si/C composites were scratched off 
from the copper substrate and mixed with potassium bromide $(\mathrm{KBr})$ by grinding and pressed into pellets. The morphologies of $\mathrm{Si} / \mathrm{C}$ composites were examined by scanning electron microscopy (SEM, JEOL 6700) and transmission electron microscopy (TEM, JEOL 2010). The crystal structures were evaluated on an X-ray diffraction (XRD) analyzer (PW1830, Philips) for 20 = 10$80^{\circ}$. The $\mathrm{N}_{2}$ adsorption and desorption isotherms were analyzed at $77 \mathrm{~K}$ on a Micromeritics ASAP 2020 analyzer and the Brunauer-Emmett-Teller (BET) method was used to determine the surface areas. To evaluate whether Si contained any impurity phases, the three Si/C electrodes were peeled off from the $\mathrm{Cu}$ foil using diluted acid and analyzed the bottom surfaces on an energy-dispersive X-ray spectroscope (EDS). The thermogravimetric analysis (TGA, Q 5000) was employed to study the compositions, and the X-ray photoelectron spectroscopy (XPS, PHI5600, Physical Electronic) was applied to evaluate the surface chemical states.

The as-prepared $\mathrm{Si} / \mathrm{C}$ pellets were directly used as anodes without binders or conductive additives. The uncoated Si control electrodes were prepared by mixing the Si particles, super P and PVDF with a weight ratio of 7:2:1. 2032 coin cells were assembled in an Ar-filled glove box with Li foil as the counter electrode. A solution of $1 \mathrm{M} \mathrm{LiPF}_{6}$ dissolved in ethyl carbonate (EC): dimethyl carbonate (DMC) mixture (1:1 v:v) was used as the electrolyte and the microporous polyethylene film (Celgard 2400) was employed as the separator. The electrochemical performance was measured on a LAND 2001 CT system between 0.02 and $1.0 \mathrm{~V}$ at different current densities.

\subsection{In-situ TEM examination}

The in-situ electrochemical experiments were carried out on a JEOL 2100F TEM equipped with a Nanofactory® scanning tunneling microscope (STM)/TEM holder [24]. The uncoated Si or Si/C particles were dispersed on a gold rod of $200 \mu \mathrm{m}$ in diameter as one electrode while a tungsten wire covered with $\mathrm{Li}$ metal was used as the counter electrode. The holder with the electrode/counter electrode assembly was quickly transferred to the TEM column while protecting the assembly with Ar gas flow. During this process, a thin layer $\mathrm{Li}_{2} \mathrm{O}$ was believed to form as solid electrolyte for the nano-cell configuration. Lithiation took place when the Au rod was driven to contact with the $\mathrm{Li}_{2} \mathrm{O} / \mathrm{Li}$ cathode while a negative bias was applied to the $\mathrm{Si} / \mathrm{C}$ anode allowing $\mathrm{Li}$ ion transport through the solid electrolyte.

\section{Results and discussion}




\subsection{Structure and morphology of $\mathrm{Si} / \mathrm{C}$ composites}

The as-supplied $\mathrm{Si}$ particles were severely agglomerated, requiring dispersion and surface functionalization before mixing with the polymer precursor [22]. The amino-silane groups (Figure S1) were shown to form covalent chemical bonds with Si particles, which helped ameliorate the particle dispersion and interactions with the polymer [32]. Figure 1a schematically illustrates the synthesis of $\mathrm{Si} / \mathrm{C}$ electrodes. The carbonization of PVDF-coated Si particles in a $\mathrm{N}_{2}$ atmosphere led to the formation of composite nanospheres consisting of a crystalline $\mathrm{Si}(\mathrm{c}-\mathrm{Si}$ ) core and an amorphous carbon (a-C) shell. One of the main advantages of the current method compared to the previous multi-step preparation of carbon-coated Si particles [17-21] is the use of as-synthesized freestanding films as anode without further treatment or binders/additives, potentially reducing the manufacturing costs. The morphologies of the final $\mathrm{Si} / \mathrm{C}$ composites are shown in Figures $1 \mathrm{~b}$-e and S2. The SEM image (Figure 1b) shows a Si/C-750 composite film of thickness $\sim 23 \mu \mathrm{m}$ attached to the $\mathrm{Cu}$ foil. The film was not a tightly-packed solid, but was an assembly of spherical $\mathrm{Si} / \mathrm{C}$ nanoparticles with interconnected pores in between (Figure 1c). These macropores can allow easy permeation of the electrolyte while accommodating the volume expansion of $\mathrm{Si} / \mathrm{C}$ particles during discharge $[23,33]$. The individual Si spheres of diameters $50-100 \mathrm{~nm}$ were joined by the amorphous carbon coating with a thickness about $6 \mathrm{~nm}$ (Figures 1d and e). The carbon shell functioned not only as buffer to accommodate the volume expansion/contraction of Si particles, but also as conductive path to enhance the electronic/ionic transport [14-20]. The SAED pattern (inset of Figure 1d) indicates the crystalline nature of the Si core. Note that the degree of PVDF graphitization depended on the carbonization temperature, the PVDF coating carbonized at 550 and $750{ }^{\circ} \mathrm{C}$ presented mainly an amorphous structure, whereas a few graphitic layers were observed on the surface of Si/C-950 (Figure S2) [34]. It should be mentioned that the degree of graphitization of carbon on Si/C-950 was still very low with a high $\mathrm{I}_{\mathrm{D}} / \mathrm{I}_{\mathrm{G}}$ intensity ratio of 2.51 according to the Raman spectra (Figure $S 4 a$ ), where the $I_{D} / I_{G}$ ratio measures the disorder in carbon.

The representative XRD patterns of three different composites are shown in Figure 2a, where the dominant diffraction peaks are assigned to the crystalline Si (PDF: 27-1402) and Cu (PDF: 040836) substrate. It's interesting to note that as the carbonization temperature increased from 750 to $950{ }^{\circ} \mathrm{C}$, the peak at $\sim 43^{\circ}$ significantly intensified as a result of thermal reactions taking place between $\mathrm{Si}$ and $\mathrm{Cu}$ at a high temperature to form copper silicide ( $\mathrm{Cu}_{6.69} \mathrm{Si}$, PDF: 51-0915) [35]. 
The small peak at $36^{\circ}$ is attributed to $\mathrm{Cu}_{0.83} \mathrm{Si}_{0.17}$ (PDF: 23-0223) [16]. The minor copper silicide is thought to be beneficial because they can improve the contact and prevent delamination between the $\mathrm{Si} / \mathrm{C}$ particles and the $\mathrm{Cu}$ current collector during cycling, but the reaction products have to be kept minimum to avoid the over consumption of active materials. The EDS analyses shown in Figure $\mathrm{S} 3$ indicate that the $\mathrm{Si} / \mathrm{C}-550$ electrodes were not doped by $\mathrm{Cu}$ during the thermal treatment, while $\mathrm{Cu}$-containing impurities were formed at the bottom surfaces of the Si/C-750 and Si/C-950 electrodes, in agreement with the XRD results. No prominent peaks were observed for a-C, probably due to its low content and amorphous nature [36]. The lattice parameters of Si calculated using the Bragg's law with an estimated error of $4 \times 10^{-4} \AA$ [33] were 5.4314, 5.4313, 5.4321 and $5.4323 \AA$ for pristine $\mathrm{Si}, \mathrm{Si} / \mathrm{C}-550, \mathrm{Si} / \mathrm{C}-750$ and Si/C-950, respectively. The slightly increased lattice parameters for Si/C-750 and Si/C-950 may have been caused by the stresses generated during the thermal treatment due to the difference in coefficient of thermal expansion between the native oxide, C layer $\left(1.3-7.0 \times 10^{-6} \mathrm{~K}^{-1}\right)$ [37] and $\mathrm{Si}$ core $\left(2.59 \times 10^{-6} \mathrm{~K}^{-1}\right)$ [38], in consistent with previous reports $[16,39]$. The comparison of pore size distribution curves between the uncoated $\mathrm{Si}$ and $\mathrm{Si} / \mathrm{C}$ (Figure $2 \mathrm{~b}$ ) clearly indicates that the carbon shell was mainly mesoporous with a dominant pore size of $\sim 3 \mathrm{~nm}$. Both the BET surface area and the pore volume of Si/C-750, 122.7 $\mathrm{m}^{2} \mathrm{~g}^{-1}$ and 0.285 , were a few times larger than those of the uncoated $\mathrm{Si}, 37.3 \mathrm{~m}^{2} \mathrm{~g}^{-1}$ and $0.095 \mathrm{~cm}^{3}$ $\mathrm{g}^{-1}$ (Table S1) [36, 40]. The surface chemistries were probed by XPS, as shown in Figures 2c-d, and the corresponding elemental compositions are summarized in Table S1. The strong F1s peak at $686.7 \mathrm{eV}$ for Si/PVDF almost totally disappeared after carbonization (Figure 2c), indicating that the fluorine present in PVDF polymer outgassed during carbonization to create mesopores in the carbon shell. Note that the residual amount of $\mathrm{F}$ was dependent on carbonization temperature so that it continuously decreased with an increase in carbonization temperature (Table S1). The deconvoluted C1s spectra show that the $-\mathrm{CF}_{2}(290.5 \mathrm{eV})$ and $-\mathrm{CH}_{2}(286.1 \mathrm{eV})$ peaks of PVDF disappeared and an amorphous carbon C-C $(284.2 \mathrm{eV})$ peak emerged after the thermal treatment [41]. These observations are in agreement with the formation of D- (disorder) and G- (graphitic) bands in Raman spectra while they were absent in Si/PVDF precursor composites (Figure S4a). The thermal characteristics of Si/C-750 composites were studied by TGA (Figure S4b): the gradual weight reduction below $\sim 300{ }^{\circ} \mathrm{C}$ is attributed to the release of adsorbed gasses and moisture in porous carbon [42] while the sudden weight drop between 520 and $650{ }^{\circ} \mathrm{C}$ refers to the oxidization of carbon. In fact, the uncoated Si particles may not be oxidized below $650{ }^{\circ} \mathrm{C}$ according to the 
previous report [43]. Thus, it can be said that the weight content of $\mathrm{Si}$ in the composite was about $81 \%$.

\subsection{Electrochemical performance of $\mathrm{Si} / \mathrm{C}$ composite electrodes}

Figure 3a shows the galvanostatic charge/discharge profiles of the uncoated $\mathrm{Si}$ and $\mathrm{Si} / \mathrm{C}-750$ electrodes measured between 0.02 and 1.0 V. The uncoated Si delivered a high initial discharge capacity of $3020 \mathrm{mAh} \mathrm{g}^{-1}$ with a long plateau at $0.05 \mathrm{~V}$ owing to Li-Si alloying at $0.2 \mathrm{~A} \mathrm{~g}^{-1}$. The discharge capacity is lower than the theoretical capacity of $3579 \mathrm{mAh} \mathrm{g}^{-1}$ similar to many previous reports [14-16], which can be explained by a few reasons, including the formation of amorphous $\mathrm{Li}_{x} \mathrm{Si}$ instead of crystalline $\mathrm{Li}_{15} \mathrm{Si}_{4}$ during discharge [28, 31], oxidization of Si NPs [16] and partial utilization of active materials. Its initial reversible capacity was $2144 \mathrm{mAh} \mathrm{g}^{-1}$ with a low Coulombic efficiency of $70.9 \%$. The large irreversible capacity lose can be explained by several possible reasons, such as the formation of thick SEI layers, the disconnection of some Si particles from the conductive additives and the trapping of $\mathrm{Li}$ ions within the active particles during delithiation [3-6]. The profile of the Si/C-750 electrode in the first cycle at $0.2 \mathrm{~A} \mathrm{~g}^{-1}$ showed lithiation/delithiation behavior similar to the uncoated Si electrode. It delivered an initial reversible capacity of $2707 \mathrm{mAh} \mathrm{g}^{-1}$ with a higher Coulombic efficiency of $88 \%$. After 5 cycles, the reversible capacity of the uncoated Si electrode was almost negligible, $80.8 \mathrm{mAh} \mathrm{g}^{-1}$. In contrast, the charge/discharge profiles of the $\mathrm{Si} / \mathrm{C}-750$ electrode at $0.5 \mathrm{~A} \mathrm{~g}^{-1}$ in the following cycles were very stable with excellent reversible capacities of 2382 and $2057 \mathrm{mAh} \mathrm{g}^{-1}$ at the $3^{\text {rd }}$ and $40^{\text {th }}$ cycle, respectively. It should be noted that both the uncoated $\mathrm{Si}$ and $\mathrm{Si} / \mathrm{C}$ electrodes were subjected to two cycles at $0.2 \mathrm{~A} \mathrm{~g}^{-1}$ before cycling at $0.5 \mathrm{~A} \mathrm{~g}^{-1}$.

To better understand the stability of Si/C particles over uncoated Si, their ex-situ SEM and TEM images were taken after 5 cycles, as shown in Figure S5. In the case of uncoated Si, Si particles were covered with thick SEI layer and cracks were formed through the electrode thickness (Figure S5a), suggesting pulverization and mechanical damage to the whole electrode during cycles (Figure S5c) [3]. The typical TEM image revealed large voids within the Si particles (Figure S5e), possibly a consequence of the coalescence of vacancies generated by the extraction of Li ions. The isolated, conductive super $\mathrm{P}$ particles are also seen among the Si particles, signifying disrupted electron/ion transfer between them during the lithiation/delithiation process [44], leading to electrical isolation of Si particles. Note that SEI was washed off by diluted acid before TEM 
analysis [14]. In contrast, the connected $\mathrm{Si} / \mathrm{C}-750$ particles with an intact spherical structure are clearly seen from the SEM and TEM images (Figures S5b, $d$ and f), indicating that the carbon shell effectively helped to prevent the pulverization of Si nanoparticles [14]. The structural durability of the electrode was confirmed by the undamaged Si particles due to the protection by the carbon coating (Figure S5f), leading to enhanced electrochemical stability of the electrode [13-16].

The influence of carbonization temperature was studied on cyclic performance of the three different Si/C composite electrodes, as shown in Figure 3b. For the activation of the electrodes, two initial charge/discharge cycles were carried out at a low current density of $0.2 \mathrm{~A} \mathrm{~g}^{-1}$. The lower capacities delivered by Si/C-950 at $0.2 \mathrm{~A} \mathrm{~g}^{-1}$ may result from the formation of electrochemically inert copper silicide, as discussed above. When cycled at $0.5 \mathrm{~A} \mathrm{~g}^{-1}$, the three electrodes exhibited very similar, high reversible capacities of 2309, 2382 and $2330 \mathrm{mAh} \mathrm{g}^{-1}$ for the Si/C-550, Si/C750 and $\mathrm{Si} / \mathrm{C}-950$ electrodes, respectively. The overall performance was the best for the Si/C-750 electrode which delivered a notable reversible capacity of $2003 \mathrm{mAh} \mathrm{g}^{-1}$ with capacity retention of $84 \%$ after 50 cycles and a high average Coulombic efficiency of $98.4 \%$ [21-23]. The residual volumetric capacity (VC) of the $\mathrm{Si} / \mathrm{C}-750$ electrode was $\sim 871 \mathrm{mAh} \mathrm{cm}^{-3}$, corresponding to the specific capacity of $2003 \mathrm{mAh} \mathrm{g}^{-1}$, for an average mass loading of $\sim 1.0 \mathrm{mg} \mathrm{cm}^{-2}$ and a thickness of $\sim 23 \mu \mathrm{m}$ (Figure 1b). The VC value obtained here is much higher than those of other Si-based electrodes [14-15, 45-46] or that of graphite anodes, $550 \mathrm{mAh} \mathrm{cm}^{-3}$ [47].

The rate performance and high rate capacities of the $\mathrm{Si} / \mathrm{C}-750$ electrode are shown in Figure $3 \mathrm{c}$. When the current density was increased 40 -folds from 0.1 to $4.0 \mathrm{~A} \mathrm{~g}^{-1}$, the ensuing capacity was reduced to $775 \mathrm{mAh} \mathrm{g}^{-1}$ at the $30^{\text {th }}$ cycle. The charge/discharge profiles of the electrode obtained at different current densities (inset Figure 3c) show characteristics of amorphous $\mathrm{Si}-\mathrm{Li}$ alloying/dealloying processes. When the current density was recovered to $0.2 \mathrm{~A} \mathrm{~g}^{-1}$ after 30 cycles, the electrode sustained a remarkable reversible capacity of $2383 \mathrm{mAh} \mathrm{g}^{-1}$ at $35^{\text {th }}$ cycle. To demonstrate its high-rate stability, the electrode was subjected to another 200 cycles at $4.0 \mathrm{~A} \mathrm{~g}^{-1}$ following the step-wise rate tests. It is worth noting that there was almost no capacity degradation for 200 cycles. The exceptional high-rate capacities and cyclic stability of the Si/C-750 electrode (Figures 3b-c) are attributed to the synergy arising from the high capacity Si core and conductive carbon shell, such as the fast electron/ion transport through the carbon networks, the formation of 
stable SEI layers during the pre-rate cycles [42], as well as the mechanical flexibility of the electrode offered by the moderate carbonization temperature [12].

The aforementioned cyclic stability and rate capacities of the Si/C-750 electrode are among the best when the electrochemical properties are compared between the various $\mathrm{Si} / \mathrm{C}$ composite electrodes reported in the literature, as shown in Table S2 and Figure S6. The electrodes made from the $\mathrm{Si} / \mathrm{C}$ yolk/shell structure [18], C scaffold/Si [36] and the $\mathrm{Si} / \mathrm{rGO} / \mathrm{Ni}$ composite foam [48] delivered marginally higher capacities at current densities above $2 \mathrm{~A} \mathrm{~g}^{-1}$ than the present Si/C-750 electrode. Nevertheless, their complicated and costly synthesis procedures may not be as appealing nor favorable for real-world applications as the one-pot carbonization process employed in the current study. Although large improvements in cyclic stability and Coulombic efficiency have been achieved by carbon coating of $\mathrm{Si}$ in this work, further studies are still needed for better optimization of the $\mathrm{Si} / \mathrm{C}$ electrodes with long-term cyclic performance.

\subsection{In-situ TEM examination}

Although the carbon coating has been demonstrated to significantly improve the electrochemical performance of Si electrodes in this work and previously [12-21], the underlying mechanisms are still elusive. It is vital to understand how the carbon coating affects the structural evolution, reaction kinetics and degradation mechanisms of Si particles during lithiation. Here, we employed an in-situ TEM device to reveal in real-time the electrochemical lithiation of uncoated $\mathrm{Si}$ and $\mathrm{Si} / \mathrm{C}$ particles. The Si/C-750 electrode was selected and designated as Si/C for the in-situ experiments. The electrode was configured as schematically illustrated in Figure S7, and a negative potential of $-2 \mathrm{~V}$ basing versus $\mathrm{Li}^{+} / \mathrm{Li}$ was applied to the working electrode to allow lithiation.

Figures 4a-d and Movie S1 depict the lithiation process of an individual uncoated Si particle designated as \#1 which had a spherical shape with $\sim 122 \mathrm{~nm}$ in diameter prior to lithiation. After $25 \mathrm{~s}$ of lithiation, an amorphous $\mathrm{Li}_{x} \mathrm{Si}\left(\mathrm{a}-\mathrm{Li}_{\mathrm{x}} \mathrm{Si}\right)$ shell with a bumpy surface was formed around the irregularly-shaped crystalline $\mathrm{Si}$ (c-Si) core as a result of anisotropic lithiation (Figure 4b). After lithiation for $65 \mathrm{~s}$, the c-Si core became facet-shape (Figure 4c), another evidence of anisotropic reactions between the c-Si and $\mathrm{Li}$ ions [26-27]. After a crack was initiated from the surface of lithiated region, more cracks were formed at different locations of the particle, as indicated by red arrows (Figure 4c). As the lithiation was continued inwards, the multiple cracks further grew, eventually leading to pulverization of the particles into several pieces (Figure 4d). The SAED 
pattern shown in Figure S8 confirmed that the fully lithiated product was $\mathrm{Li}_{15} \mathrm{Si}_{4}$. The above observations are in good agreement with the previous reports on lithiation of neat Si particles [2527].

The initial lithiation process of the $\mathrm{Si} / \mathrm{C}$ particles was examined under the same condition and illustrated by a series of time-resolved TEM images in Figures 4e-h captured from Movie S2. Two $\mathrm{Si} / \mathrm{C}$ particles designated as \#2 and \#3 with Si core diameters of $\sim 128$ and $40 \mathrm{~nm}$, respectively, coated with a uniform a-C layer of $\sim 6 \mathrm{~nm}$ were selected for examination (Figure $4 \mathrm{e}$ ). After $10 \mathrm{~s}$ of lithiation in \#2 particle, a thin layer of a- $\mathrm{Li}_{\mathrm{x}} \mathrm{Si}$ phase was formed between the dark c-Si core and light a-C shell (Figure 4f). The morphologies of both a-Lix $\mathrm{Si}$ and c-Si remained spherical, suggesting an isotropic lithiation process so far [29]. Upon lithiation and expansion of Si NPs, a compressive stress was generated in the radial direction of carbon coating [29, 49]. Further lithiation resulted in the expansion of the carbon shell with an enlarged diameter, as seen in Figure 4f. Moreover, the thickness of carbon coating slightly increased from $\sim 6 \mathrm{~nm}$ to $\sim 8 \mathrm{~nm}$, possibly due to the lithiation of a- $\mathrm{C}$ and the expansion of $\mathrm{Si}$ core [49]. The lithiation resulted in inward migration of the two phase interface between c-Si and a- $\mathrm{Li}_{\mathrm{x}} \mathrm{Si}$, and after $30 \mathrm{~s}$, the spherical a-Li $\mathrm{Li}_{\mathrm{X}} \mathrm{Si}$ layer became substantially thick on the surface of c-Si core. The c-Si core started displaying a few facets, as highlighted by a white arrow (Figure 4g), as a consequence of anisotropic lithiation similar to the uncoated $\mathrm{Si}$. At the same time, a prominent crack was initiated on the carbon shell at the junction with another large particle, see the red arrow, indicating that the stress arising from Si expansion exceeded the fracture strength of the amorphous carbon coating [30]. The crack kept growing as lithiation continued, eventually leading to the fracture of the particles. Unlike the aforementioned pulverization of uncoated $\mathrm{Si}$, the $\mathrm{Si} / \mathrm{C}$ composite showed the formation of a crack only one side while the other side was intact (Figure $4 \mathrm{~h}$ ). This can be potentially beneficial in real batteries for limiting the formation of SEI layers while maintaining uninterrupted electrical conduction for $\mathrm{Si}$. It is interesting to note that the diameter $(\sim 128 \mathrm{~nm})$ of the cracked $\mathrm{Si} / \mathrm{C}$ particle was below the critical particle size of $150 \mathrm{~nm}$ reported previously [26]. The abnormal failure of the $\mathrm{Si} / \mathrm{C}$ particle can be ascribed to the carbon coating which triggered the crack to initiate and propagate into the $\mathrm{Li}_{\mathrm{x}} \mathrm{Si}$ core during lithiation. The crack initiation in carbon coating effectively released the accumulated stress and provided preferential lithiation paths to amplify the degradation of Si particle [27]. Similarly, the structural failure of Si nanowires below the critical diameter was also induced by the surface coating $[50,51]$. The \#2 particle reached full lithiation 
after $\sim 70 \mathrm{~s}$, as shown in SAED pattern (Figure S8). At that point, the \#3 particle expanded from 40 to $\sim 64 \mathrm{~nm}$ in diameter with volume expansion of $\sim 300 \%$, indicating full lithiation (Figure $4 \mathrm{~h}$ ). However, it did not fracture, due to the relatively high tolerance to mechanical stress by the smaller Si particles [26].

The transition from isotropic to anisotropic lithiation in the $\mathrm{Si} / \mathrm{C}$ particle upon initial discharge warrants further discussion. Indeed, similar transition was also observed for Ni-encapsulated $\mathrm{Si}$ nanowires [50]. A model was proposed to explain the transition phenomenon based on the concurrent reaction and plasticity [52]:

$\Delta \mathrm{G}=\Delta \mathrm{G}_{\mathrm{r}}-\mathrm{e} \phi+1 / \mathrm{x}\left(\sigma_{\mathrm{m}}^{\mathrm{Si}} \Omega^{\mathrm{Si}}-\sigma_{\mathrm{m}}^{\mathrm{LixSi}} \Omega^{\mathrm{LixSi}}\right)$

where $\Delta \mathrm{G}_{\mathrm{r}}$ is the neat free energy change of Li-Si alloying reaction and - e $\phi$ is the driving force due to the applied voltage. The last term in the bracket refers to the driving force arising from the mechanical stresses at the reaction front: $\sigma_{\mathrm{m}}{ }^{\mathrm{Si}}$ and $\sigma_{\mathrm{m}}{ }^{\mathrm{LixSi}}$ are the mean stresses induced by Si core and lithiated $\mathrm{Si}$, respectively, while $\Omega^{\mathrm{Si}}$ and $\Omega^{\mathrm{LixSi}}$ are the corresponding volumes per Si atom and unit $\mathrm{Li}_{x} \mathrm{Si}$, respectively. It was argued that at the early stage of lithiation the external force, $-\mathrm{e} \phi$, was uniformly applied to the Si core through the conductive carbon shell and played a dominant role for isotropic lithiation, resulting in the formation of a spherical $\mathrm{Li}_{\mathrm{x}} \mathrm{Si}$ shell and $\mathrm{Si}$ core. Once lithiation continued deep into the anode, the driving force brought by the external voltage significantly diminished due to the high transfer resistance by the thick $\mathrm{Li}_{\mathrm{x}} \mathrm{Si}$ shell. The reaction would then be controlled by the intrinsic free energy change, $\Delta \mathrm{G}_{\mathrm{r}}$, so that the reaction rates became different at different crystal planes [27]. This in turn resulted in the formation of facets with projected hexagonal symmetry. It is also argued that the isotropic expansion was partly attributed to the lithiation-induced stress from the carbon coating, which in turn helped to reduce the anisotropic expansion by increasing the hydrostatic pressure at the reaction front and slowing down the anisotropic lithiation kinetics [50]. The transition signifies that highly conductive carbon coating played an important role in initial lithiation dynamics of Si particles.

It is worth noting that the \#2 Si/C particle was fully lithiated much quicker than the \#1 uncoated Si particle (70 s vs $130 \mathrm{~s}$ ) (Figure 4), although their sizes were pretty much similar ( 122 nm vs $\sim 128 \mathrm{~nm}$ ), suggesting an enhanced lithiation rate by carbon coating. To eliminate the effect of carbon coating on lithiation kinetics, we took another in-situ TEM observation of the two kind 
particles with exactly the same Si diameter of $\sim 145 \mathrm{~nm}$ [51]. Typical lithiation processes as well as the measured thicknesses of the lithiated regions as a function of time are summarized in Figure 5. The lithiation behaviors of these particles are similar to those described in Figure 4. Figure $5 \mathrm{~g}$ clearly shows that the thickness of lithiated Si layer increased much faster in Si/C than uncoated $\mathrm{Si}$, in other words, the lithiation process was faster in the $\mathrm{Si} / \mathrm{C}$ particles to reach full lithiation than the uncoated Si particle, i.e. $~ 80$ s vs 370 s, in agreement with the results shown in Figure 4. This is the first report comparing the lithiation thicknesses between the $\mathrm{Si} / \mathrm{C}$ and uncoated Si electrodes although the measurement for neat Si particles has been reported previously [27]. The faster lithiation is partly attributed to the higher diffusion coefficient of $\mathrm{Li}$ ions in a-C than $\mathrm{Si}$, i.e. $\sim 10^{-7}$ [53] vs $\sim 10^{-12} \mathrm{~cm}^{2} \mathrm{~s}^{-1}[5,29]$ and good electrical contact between Si core and carbon shell [49]. These findings are the testament to the much higher rate capabilities of $\mathrm{Si} / \mathrm{C}$ particles than neat $\mathrm{Si}$ [14-23]. Another interesting observation is that the thickness of lithiation product increased rapidly in the $\mathrm{Si} / \mathrm{C}$ particle after the crack initiation on its surface (Figure 5e), owing possibly to the penetration of Li ion through the cracks [27], which needs further investigation in the future. To mitigate the mechanical failure of the carbon-coated Si particles, several strategies can be devised, such as $\mathrm{Si} / \mathrm{C}$ composites with small Si crystals below $15 \mathrm{~nm}$ [14], porous Si/C particles [17] and $\mathrm{Si} / \mathrm{C}$ yolk-shell structure with an empty space around the Si particle [18, 31].

The above discussion signifies the importance of carbon coating on lithiation mechanisms of $\mathrm{Si}$ particles and offers direct evidence to the enhanced electrochemical performance of the $\mathrm{Si} / \mathrm{C}$ composite electrodes. It should be pointed out, however, that the electrode/electrolyte interface in real batteries is different from that of the nano-cell used in in situ TEM [51]. In real batteries, the $\mathrm{Si} / \mathrm{C}$ particles are surrounded by liquid electrolyte and SEI layers are formed during the lithiation process, thus the early and aggressive fracture of $\mathrm{Si} / \mathrm{C}$ particles seldom takes place. Even so, the in-situ TEM experiments of the open-cell configuration offer an invaluable insight into how the carbon coating on Si electrodes enhances the lithiation kinetics with faster diffusion of Li ions and how it modifies the lithiation dynamics of isotropic to anisotropic transition along with associated fracture of Si particles in real batteries.

\section{Conclusions}


In summary, high capacity $\mathrm{Si} / \mathrm{C}$ composites with enhanced cyclic stability and rate capability were synthesized in this work by one-pot carbonization of the mixture containing commerciallyavailable Si particles and PVDF. In-situ TEM experiments were carried out to disclose the roles of the carbon coating on $\mathrm{Si}$ particles during lithiation. It is revealed that the carbon-coated $\mathrm{Si}$ particles undergo a transition from isotropic to anisotropic at the initial lithiation stage. The carbon coating fully encapsulated the Si particles significantly promotes the lithiation process of $\mathrm{Si}$ electrodes. The lithiation rate was 3-4.5 times faster for the $\mathrm{Si} / \mathrm{C}$ electrodes than the uncoated $\mathrm{Si}$ counterpart, depending on the thickness of lithiation product. The flexible, amorphous carbon coating also modified the damage mode of Si particles from multiple-crack pulverization to singlecrack fracture. The above findings for the first time elucidated the effects of carbon coating on $\mathrm{Si}$ particles, which in turn provide a practical guideline for the designs of carbon coatings for enhanced electrochemical performance of Si-based electrodes.

\section{Acknowledgements}

This project was financially supported by the Research Grants Council (GRF projects 613612 and 16212814) and the Innovation and Technology Commission (ITF project ITS/318/14) of Hong

Kong SAR. The authors also appreciate the technical assistance from the Advanced Engineering Materials Facilities (AEMF) and the Materials Characterization and Preparation Facilities (MCPF) at HKUST. Part of the in situ TEM work was carried out when Z.L.X. was visiting Zhejiang University. H.W. acknowledges the financial support from the National Science Foundation of China (Grant No. 11322219 and 11321202).

\section{Reference}

[1] M. Armand, J. M. Tarascon, Building better batteries, Nature 451 (2008) 652.

[2] H. D. Yoo, E. Markevich, G. Salitra, D. Sharon and D. Aurbach, On the challenge of developing advanced technologies for electrochemical energy storage and conversion, Materials Today 17 (2014) 110-121.

[3] U. Kasavajjula, C. Wang, A. J. Appleby, Nano- and bulk-silicon-based insertion anodes for lithium-ion secondary cells, J. Power Sources 163 (2007) 1003-1039. 
[4] J.R. Szczech and S. Jin, Nanostructured silicon for high capacity lithium battery anodes, Energy Environ. Sci. 4 (2011) 56.

[5] X. Su, Q. Wu, J. Li, X. Xiao, A. Lott, W. Lu, B. W. Sheldon and J. Wu, Silicon-based nanomaterials for lithium-ion batteries: A Review, Adv. Energy Mater. 4 (2013) 1-23.

[6] H. Wu and Y. Cui, Designing nanostructured Si anodes for high energy lithium ion batteries, Nano Today 7 (2012) 414-429.

[7] C.K. Chan, H. Peng, G. Liu, K. Mcllwarth, X. F. Zhang, R. A. Huggins and Y. Cui, Highperformance lithium battery anodes using silicon nanowires, Nat. Nanotech. 3 (2008) 31-35.

[8] H. Wu, G. Chan, J. W. Choi, I. Ryu, Y. Yao, M. T. McDowell, S. W. Lee, A. Jackson, Y. Yang, L. Hu and Y. Cui, Stable cycling of double-walled silicon nanotube battery anodes through solidelectrolyte interphase control, Nat. Nanotech. 7 (2012) 310-315.

[9] Y. Yao, M. T. McDowell, I. Ryu, H. Wu, N. Liu, L. Hu, W. D. Nix and Y. Cui, Interconnected silicon hollow nanospheres for lithium-ion battery anodes with long cycle life, Nano Lett. 11 (2011) 2949-2954.

[10] X. Huang, J. Yang, S. Mao, J. Chang, P. B. Hallac, C. R. Fell, B. Metz, J. Jiang, P. T. Hurley and J. Chen, Controllable synthesis of hollow Si anode for long-cycle-life lithium-ion batteries, Adv. Mater. 26 (2014): 4326-4332.

[11] X. Li, C. Yan, J. Wang, A. Graff, S. L. Schweizer, A. Sprafke, O. G. Schmidt and R. B. Wehrspohn, Stable silicon anodes for lithium-ion batteries using mesoporous metallurgical silicon, Adv. Energy Mater. 2014, 1401556.

[12] N. Dimov, S. Kugino and M. Yoshio, Carbon-coated silicon as anode material for lithium ion batteries: advantages and limitations, Electrochem. Acta 48 (2003) 1579-1587.

[13] M. L. Terranova, S. Orlanducci, E. Tamburri, V. Guglielmotti, M. Rossi, Si/C hybrid nanostructures for Li-ion anodes: an overview, J. Power Sources 246 (2014) 167-177.

[14] R. Yi, F. Dai, M. L. Gordin, H. Sohn and D. Wang, Influence of silicon nanoscale building block size and carbon coating on the performance of micro-sized Si-C composite Li-ion anodes, Adv. Energy Mater. 3 (2013) 1507-1515. 
[15] Z. Zhang, Y. Wang, W. Ren, Q. Tan, Y. Chen, H. Li, Z. Zhong and F. Su, Scalable synthesis of interconnected porous silicon/carbon composites by Rochow reaction as high-performance anodes of lithium ion batteries, Angew. Chem. Int. Ed. 53 (2014) 5165-5169.

[16] F. M. Hassan, V. Chabot, A. R. Elsayed, X. Xiao and Z. Chen, Engineered Si electrode nanoarchitechture: a scalable postfabrication treatment for the production of next-generation $\mathrm{Li}$ ion batteries, Nano Lett. 14 (2014) 277-283.

[17] X. Li, P. Meduri, X. Chen, W. Qi, M. H. Engelhard, W. Xu, F. Ding, J. Xiao, W. Wang, C. Wang, J. G. Zhang and J. Liu, Hollow core-shell structured porous Si-C nanocomposites for Liion battery anodes, J. Mater. Chem. 22 (2012) 11014.

[18] N. Liu, H. Wu, M. T. McDowell, Y. Yao, C. Wang and Y. Cui, A yolk-shell design for stabilized and scalable Li-ion batteries alloy anodes, Nano Lett. 12 (2012) 3315-3321.

[19] X. Ma, M. Liu, L. Gan, P. K. Tripathi, Y. Zhao, D. Zhu, Z. Xu and L. Chen, Novel mesoporous Si@C microspheres as anodes for lithium-ion batteries, Phys. Chem. Chem. Phys. 16 (2014) 41354142.

[20] Y. S. Hu, R. Demir-Cakan, M. M. Titirici, J. O. Muller, R. Schlogl, M. Antonietti and J. Maier, Superior storage performance of a $\mathrm{Si} @ \mathrm{SiO}_{\mathrm{x}} / \mathrm{C}$ nanocomposite as anode material for lithium-ion batteries, Angew. Chem. Int. Ed 47 (2008) 1645-1649.

[21] Y. Xu, G. Yin, Y. Ma, P. Zuo and X. Cheng, Nanosized core/shell silicon@ carbon anode material for lithium ion batteries with polyvinylidene fluoride as carbon source, J. Mater. Chem. 20 (2010) 3216-3220.

[22] Z. L. Xu, B. Zhang and J. K. Kim, Electrospun carbon nanofiber anodes containing monodispersed Si nanoparticles and graphene oxide with exceptional high rate capacities, Nano Energy 6 (2014) 27-35.

[23] Z. L. Xu, B. Zhang, S. Abouali, M. Akbari Garakani, J. Huang, J. Q. Huang, E. Kamali Heidari and J. K. Kim, Nanocavity-engineered Si/multi-functional carbon nanofiber composite anodes with exceptional high-rate capacities, J. Mater. Chem. A 2 (2014) 17944.

[24] Z. L. Xu, B. Zhang, Y. Gang, K. Cao, M. A. Garakani, S. Abouali, J. Huang, J. Q. Huang, E. K. Heidari, H. Wang and J. K. Kim, In-situ TEM examination and exceptional long-term cyclic 
stability of ultrafine $\mathrm{Fe}_{3} \mathrm{O}_{4}$ nanocrystal/carbon nanofiber composite electrodes, Energy Storage Mater. 1 (2015) 27-34.

[25] X. H. Liu, Y. Liu, A. Kushima, S. Zhang, T. Zhu, J. Li and J. Y. Huang, In-situ TEM experiments of electrochemical lithiation and delithiation of individual nanostructures, Adv. Energy Mater. 2 (2012) 722-741.

[26] X. H. Liu, L. Zhong, S. Huang, S. X. Mao, T. Zhu and J. Y. Huang, Size-dependent fracture of silicon nanoparticles during lithiation, ACS Nano 6 (2012) 1522-1531.

[27] M. T. McDowell, I. Ryu, S. W. Lee, C. Wang, W. D. Nix and Y. Cui, Studying the kinetics of crystalline silicon nanoparticle lithiation with in-situ transmission electron microscopy, Adv. Mater. 24 (2012) 6034-6041.

[28] Y. He, D. M. Piper, M. Gu, J. J. Travis, S. M. George, S. H. Lee, A. Genc, L. Pullan, J. Liu, S. X. Mao, J. G. Zhang, C. Ban and C. Wang, In Situ Transmission Electron Microscopy Probing of Native Oxide and Artificial Layers on Silicon Nanoparticles for Lithium Ion Batteries, ACS Nano 8 (2014) 11816-11823.

[29] L. Luo, J. Wu, J. Luo, J. Huang and V. P. Dravid, Dynamics of electrochemical lithiation/delithiation of graphene-encapsulated silicon nanoparticles studied by in-situ TEM, Sci. Rep. 4 (2014) 3836.

[30] M. Gu, Y. Li, X. Li, S. Hu, X. Zhang, W. Xu, S. Thevuthasan, D. R. Baer, J. G. Zhang, J. Liu and C. Wang, In situ TEM study of lithiation behavior of silicon nanoparticles attached to and embedded in a carbon matrix, ACS Nano 6 (2012) 8439-8447.

[31] X. Xiao, W. Zhou, Y. Kim, I. Ryu, M. Gu, C. Wang, G. Liu, Z. Liu and H. Gao, Regulated Breathing Effect of Silicon Negative Electrode for Dramatically Enhanced Performance of Li-Ion Battery, Adv. Funct. Mater. 25 (2015) 1426-1433.

[32] Z. Xu, J. Zhang, M. Shan, Y. Li, B. Li, J. Niu, B. Zhou and X. Qian, Organosilanefunctionalized graphene oxide for enhanced antifouling and mechanical properties of polyvinylidene fluoride ultrafiltration membranes, J. Membr. Sci. 458 (2014) 1-13. 
[33] B. Zhang, Q. Zheng, Z.D. Huang, S.W. Oh and J. K. Kim, Improved rate capability of carbon coated $\mathrm{Li}_{3.9} \mathrm{Sn}_{0.1} \mathrm{Ti}_{5} \mathrm{O}_{12}$ porous electrodes for Li-ion batteries, J. Power Sources 196 (2011) 1069210697.

[34] B. Zhang, Y. Yu, Z.D. Huang, Y.B. He, D. H. Jang, W.S. Yoon, Y.W. Mai, F.Y. Kang, J.K. Kim, Exceptional electrochemical performance of freestanding electrospun carbon nanofiber anodes containing ultrafine $\mathrm{SnO}_{x}$ particles, Energy Environ. Sci. 5 (2012) 9895-9902.

[35] C. Joyce, L. Trahey, S. A. Bauer, F. Dogan and J. T. Vaughey, Metallic copper binders for lithium-ion battery silicon electrodes, J. Electrochem. Soc. 159 (2012) A909-A914.

[36] J. Guo, X. Chen and C. Wang, Carbon scaffold structured silicon anodes for lithium-ion batteries, J. Mater. Chem. 20 (2010) 5035-5040.

[37] F. C. Marques, R. G. Lacerda, A. Champi, V. Stolojan, D. C. Cox and S. R. P. Silva, Thermal expansion coefficient of hydrogenated amorphous carbon, Appl. Phys. Lett. 83 (2003) 3099-3102.

[38] Y. Okada and Y. Tokumaru, Precise determination of lattice parameter and thermal expansion coefficient of silicon between 300 and 1500 K, J. Appl. Phys. 56 (1984) 314-322.

[39] I. M. Young, M. I. J. Beale and J. D. Benjamin, X-ray double crystal diffraction study of porous silicon, Appl. Phys. Lett. 46 (1985) 1133-1135.

[40] B. Xu, S. Hou, M. Chu, G. Cao and Y. Yang, An activation-free method for preparing microporous carbon by the pyrolysis of poly(vinylidene fluoride), Carbon 48 (2010) 2812-2814.

[41] M. D. Duca, C. L. Plosceanu and T. Pop, Effect of X-rays on poly (vinylidene fluoride) in Xray photoelectron spectroscopy, J. Appl. Polymer Sci. 67 (1998) 2125-2129.

[42] Z. L. Xu, B. Zhang, Z. Q. Zhou, S. Abouali, M. A. Garakani, J. Huang, J. Q. Huang and J. K. Kim, Carbon nanofibers containing $\mathrm{Si}$ nanoparticles and graphene-covered $\mathrm{Ni}$ for high performance anodes in Li ion batteries, RSC Adv. 4 (2014) 22359.

[43] H. H. Li, J. W. Wang, X. L. Wu, H. Z. Sun, F. M. Yang, K. Wang, L. L. Zhang, C. Y. Fan and J. P. Zhang, A novel approach to prepare $\mathrm{Si} / \mathrm{C}$ nanocomposites with yolk-shell structures for lithium ion batteries, RSC Adv. 4 (2014) 36218. 
[44] M. Gu, X. C. Xiao, G. Liu, S. Thevuthasan, D. R. Baer, J. G. Zhang, J. Liu, N. D. Browning and C. M. Wang, Mesoscale origin of the enhanced cycling-stability of Si-conductive polymer anode for Li-ion batteries, Sci. Rep. 4 (2014) 3684.

[45] H. Liu, H. M. Cho, Y. S. Meng and Q. Li, Engineering Three-Dimensionally Electrodeposited Si-on-Ni Inverse Opal Structure for High Volumetric Capacity Li-Ion Microbattery Anode, ACS Appl. Mater. Interfaces 6 (2014) 9842-9849.

[46] F. Xia, S. B. Kim, H. Cheng, J. M. Lee, T. Song, Y. Huang, J. A. Rogers, U. Paik, W. I. Park, Facile synthesis of free-standing silicon membranes with three-dimensional nanoarchitecture for anodes of lithium ion batteries, Nano Lett. 13 (2013) 3340-3346.

[47] I. H. Son, J. H. Park, S. Kwon, S. Park, M. H. Rummeli, A. Bachmatiuk, H. J. Song, J. Ku, J. W. Choi, J. Choi, S. G. Doo and H. Chang, Silicon carbide-free graphene growth on silicon for lithium-ion battery with high volumetric energy density, Nat. Commun. 6 (2015).

[48] J. Chang, X. Huang, G. Zhou, S. Cui, P. B. Hallac, J. Jiang, P. T. Hurley and J. Chen, Multilayered Si nanoparticle/reduced graphene oxide hybrid as a high-performance lithium-ion battery anode, Adv. Mater. 26 (2014) 758-764.

[49] W. J. Yu, C. Liu, P. X. Hou, L. Zhang, X. Y. Shan, F. Li and H. M. Cheng, Lithiation of silicon nanoparticles confined in carbon nanotubes, ACS Nano 9 (2015) 5063-5071.

[50] G. Sandu, L. Brassart, J. F. Gohy, T. Pardoen, S. Melinte and A. Vlad, Surface coating mediated swelling and fracture of silicon nanowires during lithiation, ACS Nano 8 (2014) 94279436.

[51] L. Luo, H. Yang, P. Yan, J. J. Travis, Y. Lee, N. Liu, D. M. Piper, S. H. Lee, P. Zhao, S. M. George, J. G. Zhang, Y. Cui, S. Zhang, C. Ban and C. M. Wang, Surface-coating regulated lithiation kinetics and degradation in silicon nanowires for lithium ion battery, ACS Nano 9 (2015) 5559-5566.

[52] K. Zhao, M. Pharr, Q. Wan, W. L. Wang, E. Kaxiras, J. J. Vlassak and Z. Suo, Concurrent reaction and plasticity during initial lithiation of crystalline silicon in lithium-ion batteries, J. Electrochem. Soc. 159 (2012) A238-243. 
[53] H. Tachikawa, A. Shimizu, Diffusion dynamics of the Li atom on amorphous carbon: a direct molecular orbital-molecular dynamics study, J. Phys. Chem. B 110 (2006) 20445-20450. 
(a)
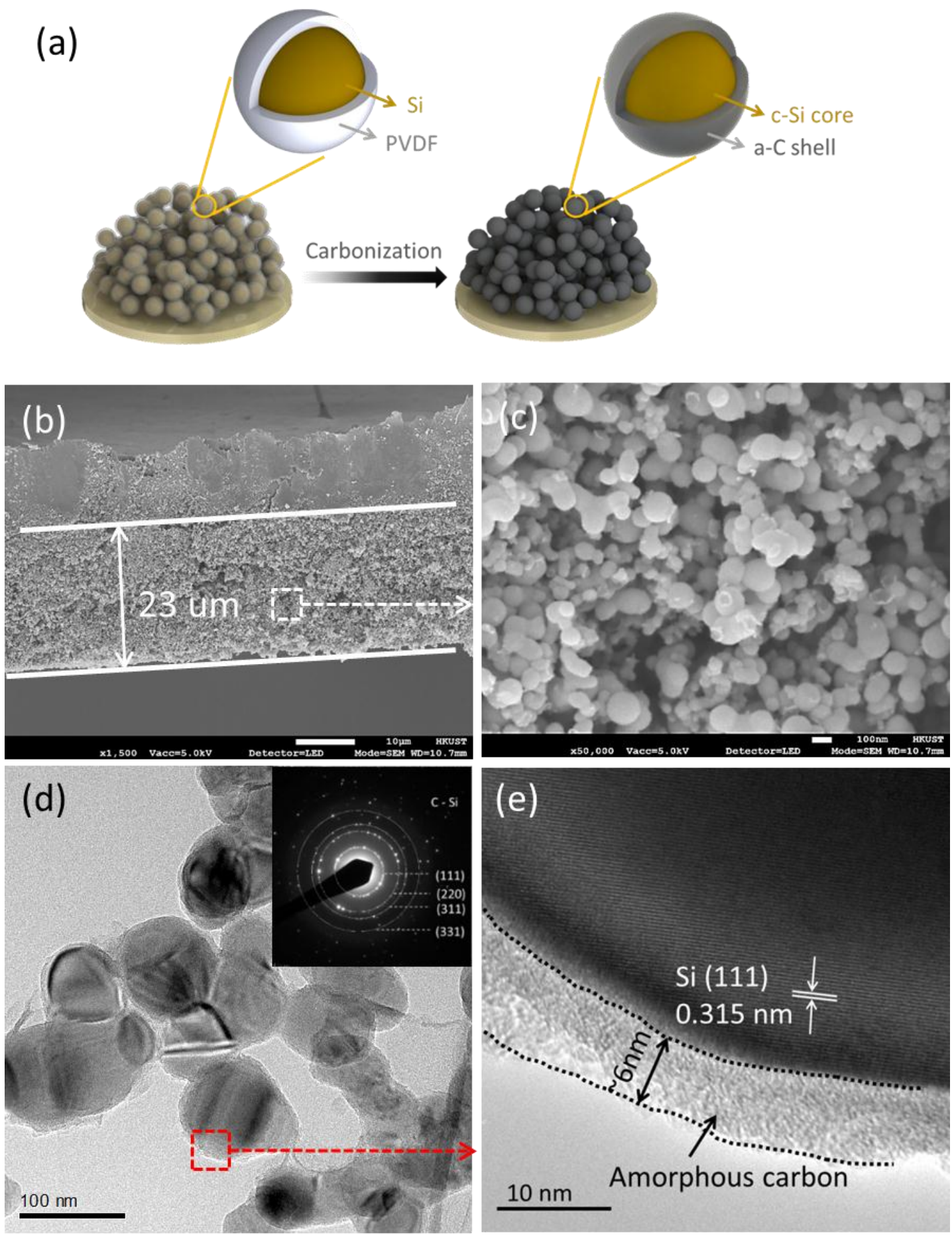

Figure 1 (a) Schematic illustration of the synthesis of Si core/C shell composites; (b-c) SEM images of Si/C composite; (d) TEM and (e) HRTEM images of Si/C particles, inset (d) is the SAED pattern of Si/C particles. 

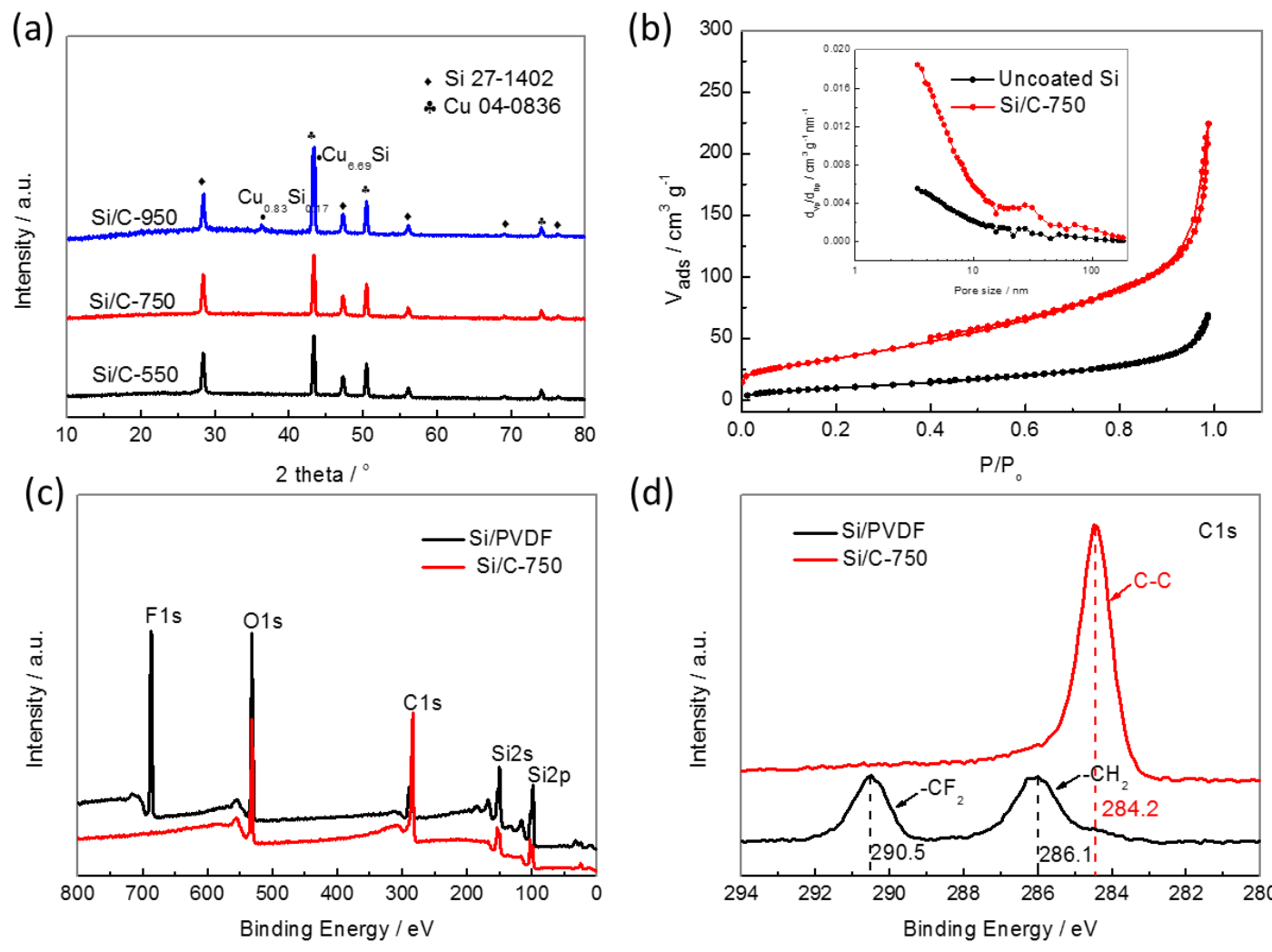

(d)

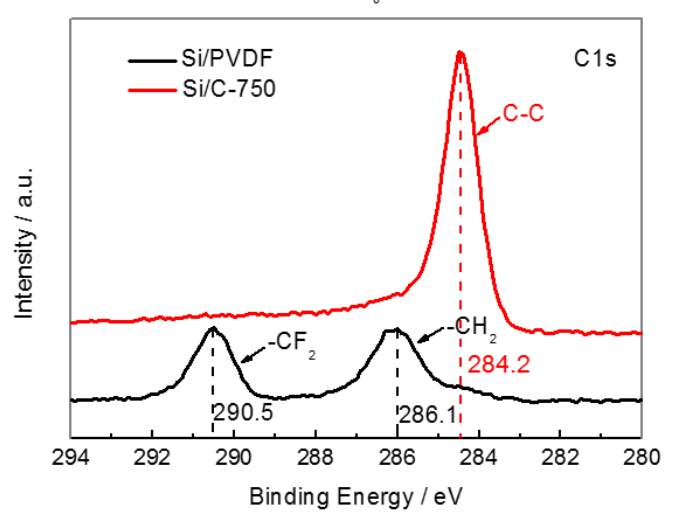

Figure 2 (a) XRD patterns of Si/C composites; (b) $\mathrm{N}_{2}$ adsorption/desorption isothermal curves and pore size distributions of uncoated $\mathrm{Si}$ and $\mathrm{Si} / \mathrm{C}$; (c) general XPS spectra of Si/PVDF precursor and Si/C composite; (d) deconvoluted C1s XPS spectra of Si/PVDF and Si/C. 

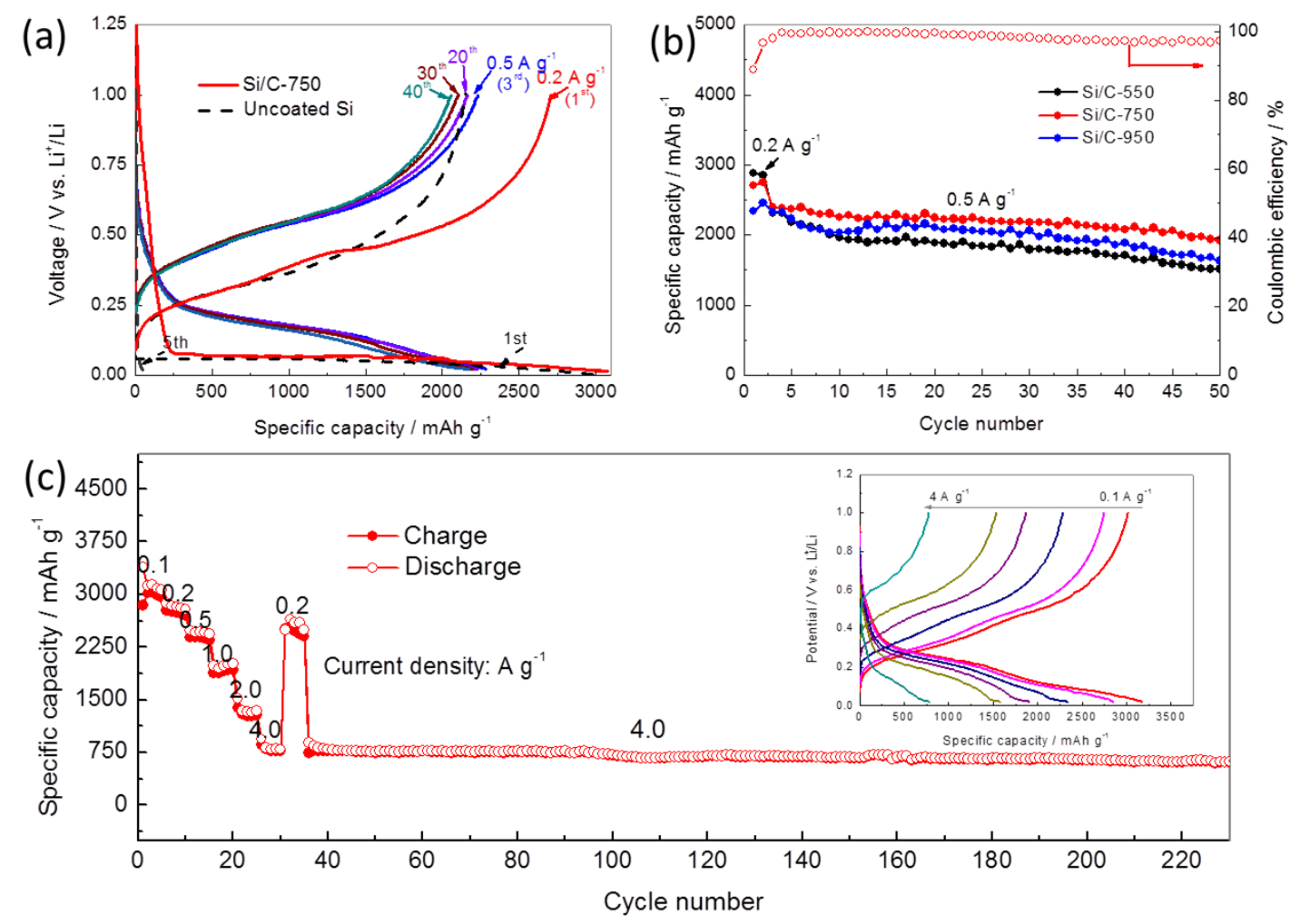

Figure 3 (a) Charge/discharge voltage profiles of uncoated $\mathrm{Si}$ and $\mathrm{Si} / \mathrm{C}-750$ electrodes between 0.02 and $1.0 \mathrm{~V}$; (b) cyclic performance of $\mathrm{Si} / \mathrm{C}$ electrodes measured at $0.5 \mathrm{~A} \mathrm{~g}^{-1}$; (c) rate capacities of $\mathrm{Si} / \mathrm{C}-750$ measured at current densities ranging $0.1-4.0 \mathrm{~A} \mathrm{~g}^{-1}$ along with cyclic stability for another 200 cycles at $4.0 \mathrm{~A} \mathrm{~g}^{-1}$, and galvanostatic charge/discharge voltage profiles at different current densities in inset. 

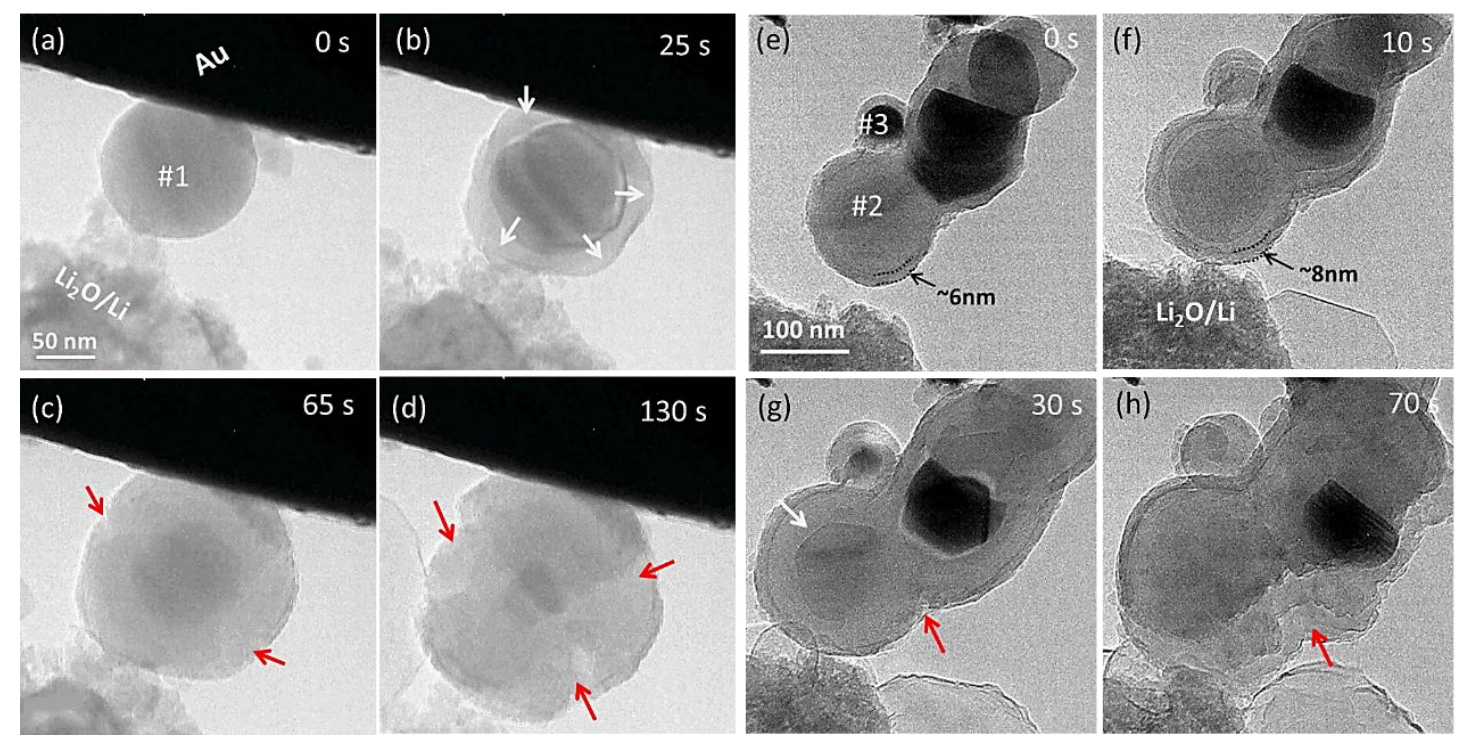

Figure 4 Time-resolved TEM images of uncoated $\mathrm{Si}$ (a-d) and $\mathrm{Si} / \mathrm{C}$ (e-h) particles during lithiation. The uncoated $\mathrm{Si}$ in (a) and $\mathrm{Si} / \mathrm{C}$ particles in (e) are designated as \#1, \#2 and \#3, respectively. The white arrows in (b) and (g) refer to bump-shaped $\mathrm{Li}_{x} \mathrm{Si}$ and faceted $\mathrm{Si}$, and the red arrows in (c-d) and (g-h) correspond to cracks. 

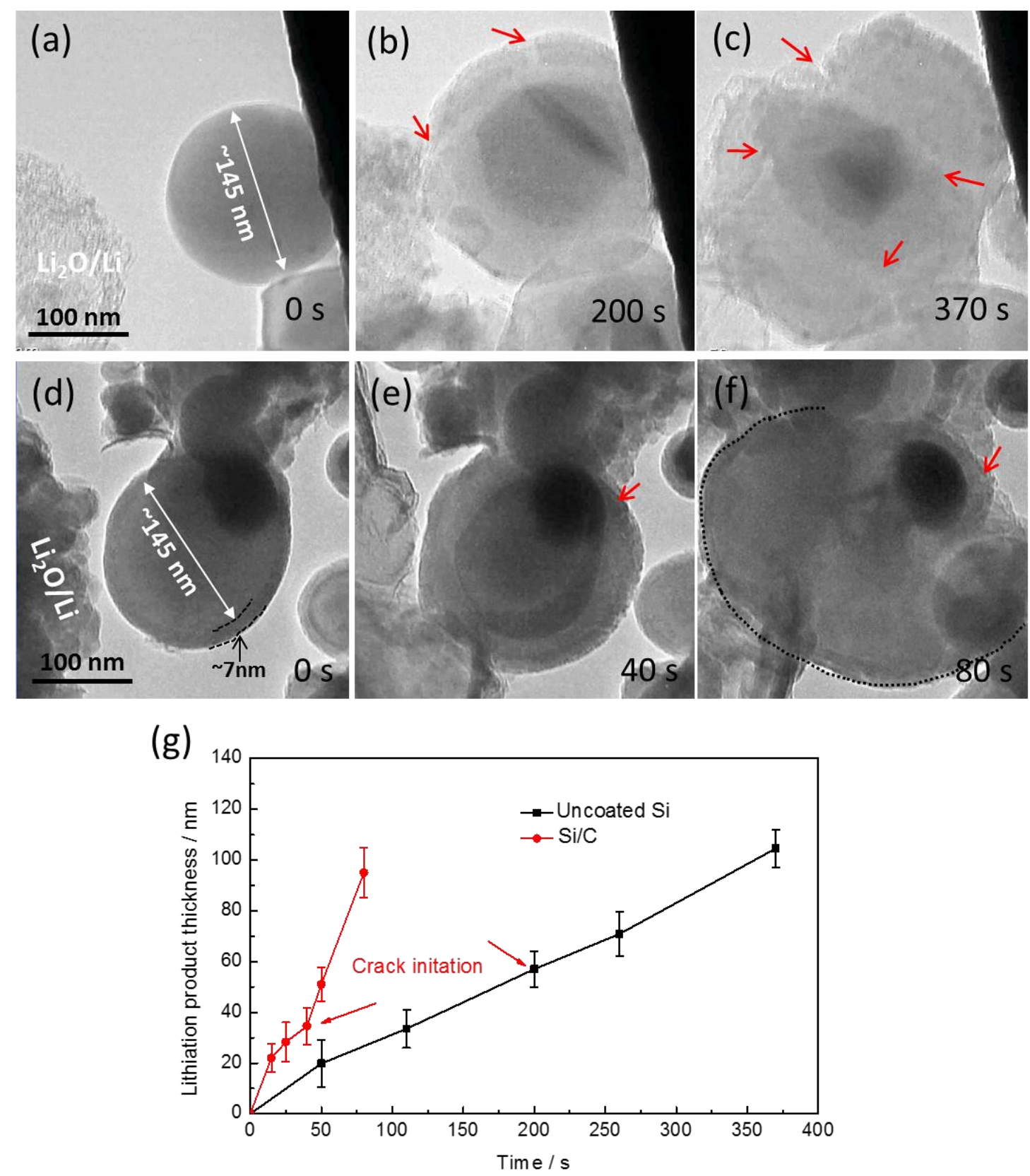

Figure 5 Time-resolved TEM images of (a-c) uncoated $\mathrm{Si}$ and (d-f) $\mathrm{Si} / \mathrm{C}$ particles with the same initial diameter of $\sim 145 \mathrm{~nm}$ and the growth of their diameters upon lithiation; (g) plots of thickness of lithiation product vs time for the uncoated $\mathrm{Si}$ and $\mathrm{Si} / \mathrm{C}$ particles, the red arrows indicate the crack initiation. 

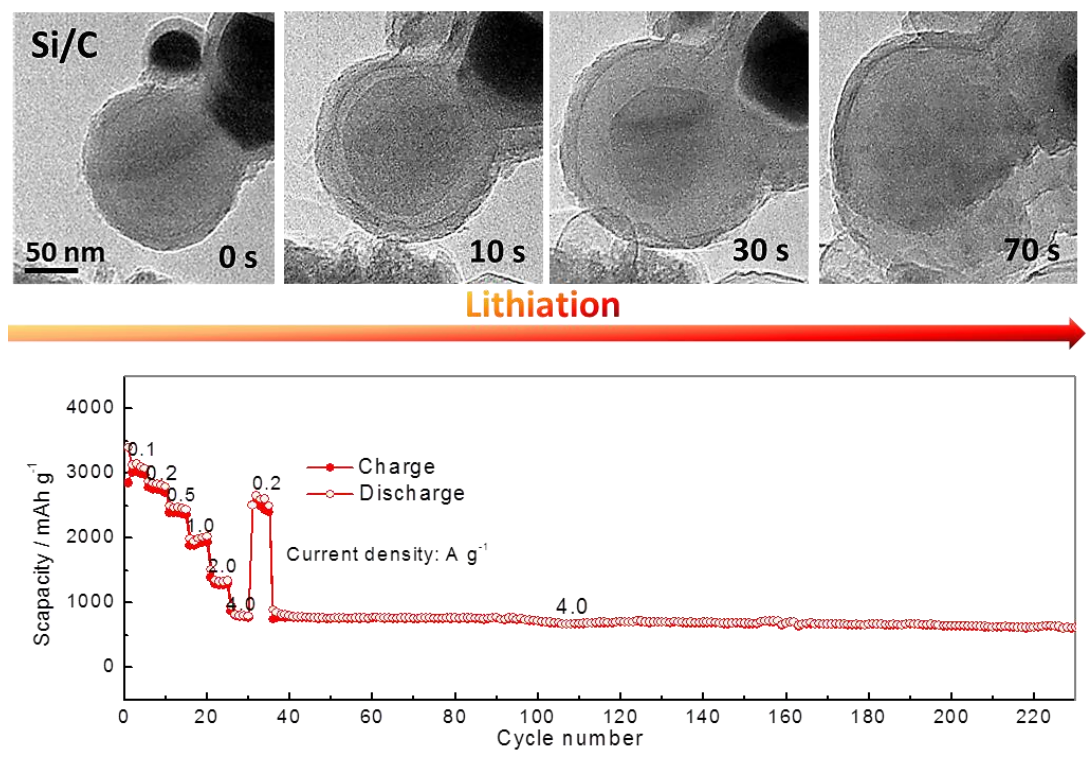